\title{
Rapid Land Subsidence in Tianjin, China Derived from Continuous GPS Observations (2010-2019)
}

\author{
Ruibin Zhao ${ }^{1}$, Guoquan Wang ${ }^{2}$, Xiao $\mathrm{Yu}^{2}$, Xiaohan $\mathrm{Sun}^{3}$, Yan $\mathrm{Bao}^{4}$, Genru Xiao ${ }^{5}$, Weijun Gan ${ }^{6}$, and \\ Shuilong Shen ${ }^{7}$ \\ ${ }^{1}$ School of Geology and Geomatics, Tianjin Chengjian University, Tianjin 300384, China \\ ${ }^{2}$ Department of Earth and Atmospheric Sciences, University of Houston, Houston 77204, USA \\ ${ }^{3}$ School of Civil Engineering, Tianjin Chengjian University, Tianjin 300384, China \\ ${ }^{4}$ Key Laboratory of Urban Security and Disaster Engineering of Ministry of Education, \\ Beijing University of Technology, Beijing 100124, China \\ ${ }^{5}$ Key Laboratory for Digital Land and Resources of Jiangxi Province, East China University \\ of Technology, Nanchang 330013, China \\ ${ }^{6}$ State Key Laboratory of Earthquake Dynamics, Institute of Geology, \\ China Earthquake Administration, Beijing 100029, China \\ ${ }^{7}$ Key Laboratory of Intelligent Manufacturing Technology of Ministry of Education, \\ Shantou University, Shantou, Guangdong 515063, China
}

Correspondence: Guoquan Wang (gwang@uh.edu)

Published: 22 April 2020

\begin{abstract}
We have delineated ten years of urban subsidence derived from continuous GPS stations operated by the Crustal Movement Observational Network of China (CMONOC) within and adjacent to the municipality of Tianjin. A method for obtaining accurate site velocities with respect to a stable regional reference frame is described. CMONOC stations in Jizhou (JIXN) and Baodi (TJBD) districts recorded minor subsidence of approximately 1 to $2 \mathrm{~mm} \mathrm{yr}^{-1}$ during the period from 2010 to 2019. One station in Wuqing (TJWQ) district and one station in Binhai (TJBH) district recorded steady subsidence of approximately 5 and $2 \mathrm{~cm} \mathrm{yr}^{-1}$ from 2010 to 2019, respectively. One station in Cangzhou (HECX) of Hebei Province, adjacent to Tianjin, recorded steady subsidence of approximately $2.4 \mathrm{~cm} \mathrm{yr}^{-1}$ during 2010-2014 and more rapid subsidence of $4 \mathrm{~cm} \mathrm{yr}^{-1}$ since 2015 . TJWQ recorded the most rapid land subsidence and the most significant seasonal ground oscillations (uplift and subsidence) among these five stations. This study indicates that subsidence rates in Tianjin vary significantly in space and time. Particular attention should be paid, therefore, to extrapolate or infer a rate of subsidence for an area on the basis of a subsidence rate obtained from previous GPS observations or proximal GPS sites. The subsidence time series presented in this study provide reliable "ground truth" and constraints for calibrating or validating subsidence estimations from numerical modeling and repeated surveys using other remote sensing techniques, such as Interferometric Synthetic Aperture Radar (InSAR).
\end{abstract}

\section{Introduction}

Tianjin, the largest port city in north China and the center of the industrial and economic area around Bohai Bay, has experienced severe subsidence problems since the 1950s (Hu et al., 2004). During the past two decades, Global Positioning System (GPS) technologies have been gradually applied to urban subsidence studies, both as a compliment and an alternative to conventional surveying methods. A great number of Continuously Operating Reference GPS Stations (CORS) have been installed in China during the past two decades. The Crustal Movement Observational Network of China (CMONOC), the largest CORS network in China, operates over 260 continuous permanent GPS stations across the China mainland (Fig. 1). 
CMONOC was designed primarily for earthquake and tectonic studies and for providing stable references for nationwide land surveying. Though CMONOC sites were carefully selected to avoid potential subsiding and faulting sites, a few CMONOC in urban areas have recorded rapid land subsidence, as a by-product. The earliest CMONOC stations were installed in the early 1990s, but the majority stations in north China were installed in 2010. As of 2019, most CMONOC stations in north China have a continuous history of approximately 8 to 10 years.

The municipality of Tianjin is situated on Quaternary and Tertiary sediments overlying the considerably fractured bedrock. The loose Quaternary sediments, composed of clay, soil, and sand, are about $600 \mathrm{~m}$ thick in the municipality of Tianjin area and are hydrogeologically complex. The Tertiary aquifer system has a depth range from approximately 600 to $1100 \mathrm{~m}$. The top $50 \mathrm{~m}$ of the Quaternary sediments are alternating marine and continental deposits of varying lithological characters and poor engineering geological properties, being mostly highly compressible. At depths from 50 to $200 \mathrm{~m}$ below the land surface, the sediments have mediumto-low compressibility characteristics expected in deposits of mainly fluvial facies. Below $200 \mathrm{~m}$, the sediments are of lacustrine facies, which change slightly in lithological character and are low compressional compared to its overlay sediments (Tianjin Geological Survey and Mine Resource Administration, 1992). Excessive groundwater pumping is the primary reason causing subsidence in Tianjin (Yi et al., 2011). In general, groundwater withdrawal within the municipality of Tianjin is restricted to a depth shallower than $550 \mathrm{~m}$ below the land surface.

There are five CMONOC stations within and adjacent to the municipality of Tianjin. This study aims to delineate the 10-year subsidence time series recorded by these five CMONOC stations from 2010 to 2019. A comparison of rapid ongoing subsidence in Tianjin, Houston, and Mexico City is presented.

\section{Methods}

The ultimate product from continuous GPS observations is often the site velocities with respect to a stable reference frame rather than discrete positional measurements. The accuracy of GPS-derived site velocities does not solely rely on the accuracy of positional measurements, but largely depends on available regional geodetic infrastructure, which is comprised of two components: a long-history continuous GPS network and a stable regional reference frame (Wang et al., 2019). The GPS data from a single station is insufficient by itself to assess the stability of the site.

GPS positions are initially defined as a set of coordinates with respect to a global reference frame. In general, a global geodetic reference frame is a no-net-rotation (NNR) reference frame, which is realized with an approach of minimiz-

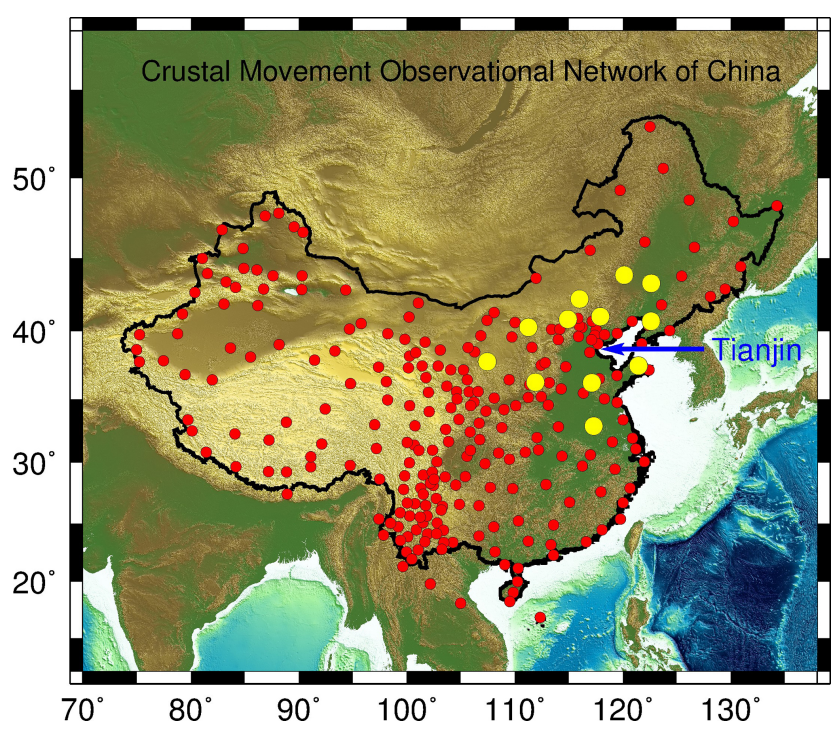

Figure 1. Map showing the locations of 260 permanent GPS stations (red) of the Crustal Movement Observational Network of China (CMONOC) and 12 reference stations (yellow) utilized to realize the stable North China Reference Frame 2016 (NChina16, Wang et al., 2018).

ing the overall horizontal movements of a large number of selected reference stations distributed worldwide (Rebischung et al., 2016). As a consequence, GPS-derived site velocities with respect to a global reference frame are often dominated by long-term drift and rotations of the tectonic plate on which the site is located, glacial isostatic adjustment, and other secular motions (Yu and Wang, 2017). Localized or temporal ground deformation, such as subsidence and fault creeping, can be obscured or biased by those common movements. A stable regional reference frame is needed to exclude those common ground motions and highlight localized ground deformation.

This study employs a method that integrates Precise Point Positioning (PPP) and a stable regional reference frame for deriving site velocities from long-term GPS observations. The details of the method have been introduced in our recent publications for monitoring landslide (Wang et al., 2014, 2015), subsidence (Kearns et al., 2019), and urban faults (Liu et al., 2019). In short, the whole process comprises the following three steps.

The first step is to get daily PPP solutions from $24 \mathrm{~h}$ continuous GPS observations. The GipsyX software package developed and maintained by the Jet Propulsion Laboratory (JPL) in the United States (US) is employed to get singlereceiver phase-ambiguity-fixed PPP solutions (Bertiger et al., 2010). The major parameters used for the PPP processing are the same as those listed in our previous publication for realizing North China Reference Frame 2016 (NChina16) (Wang et al., 2018). PPP daily solutions could achieve $2-4 \mathrm{~mm}$ horizontal accuracy (root mean square of residuals) and 5-8 $\mathrm{mm}$ 
vertical accuracy in north China (Bao et al., 2017; Guo et al., 2019). The PPP solutions are defined in an Earth-CenteredEarth-Fixed (ECEF) Cartesian coordinate system that defines a position as a pair of $x, y$, and $z$ coordinates with respect to the International GNSS Service (IGS) reference frame 2014 (IGS14) (Rebischung et al., 2016). IGS14 is the latest in a series of GNSS reference frames (e.g., IGS00, IGS05, IGS08) adopted by IGS.

The second step is to transform the IGS14 coordinates to our selected stable regional reference frame, NChina16. NChina16 was realized by 12 CMONOC stations fixed on the stable portion of north China craton (Wang et al., 2018) (Fig. 1). One-decade continuous GPS observations have verified that those reference stations are not affected by subsidence and faulting problems. NChina16 provides the 7parameters for transforming ECEF-XYZ coordinates from IGS08 to the regional reference frame. Since NChina16 is aligned to IGS08, the IGS14 coordinates are firstly transformed to IGS08 according to the parameters provided by IGS (Rebischung et al., 2016). NChina16 will be updated and aligned to IGS14 in 2020. Thus, the PPP solutions with respect to IGS14 can be directly transformed to the regional reference frame in the near future.

The third step is to convert the geocentric $x y z$ coordinates with respect to NChina16 to a local east-west (EW), northsouth (NS), and up-down (UD) coordinate system (ENU). The local ENU coordinates are formed from a plane tangent to the Earth's surface fixed to the initial location (first measurement) of the site. The change of ellipsoid height over time is used to depict the vertical displacement (subsidence) in this study. In practice, subsidence time series derived from ellipsoid heights are the same as those derived from orthometric heights (Wang and Soler, 2014).

\section{Subsidence Derived from GPS Observations}

\subsection{Subsidence rates}

In general, the accuracy of GPS-derived positions, and in turn, displacements and site velocities, have been improved dramatically over the past two decades due to advances in GPS hardware, software, and reference systems. The accuracy of site velocities is primarily dominated by the stability of the reference frame and the length of the observational history rather than the accuracy of the individual positional measurements (Wang et al., 2017). The frame stability of NChina16 is better than $1 \mathrm{~mm} \mathrm{yr}^{-1}$ in all three directions (Wang et al., 2018). Figure 2 illustrates the horizontal and vertical velocity vectors (with respect to NChina16) of nine CMONOC stations within the Beijing and Tianjin region. The velocities are estimated by applying a linear leastsquares regression on GPS-derived displacement time series from 2010 to 2019.

There are four CMONOC stations (BJGB, BJYQ, BJSH, and BJFS) within the municipality of Beijing (Fig. 2).

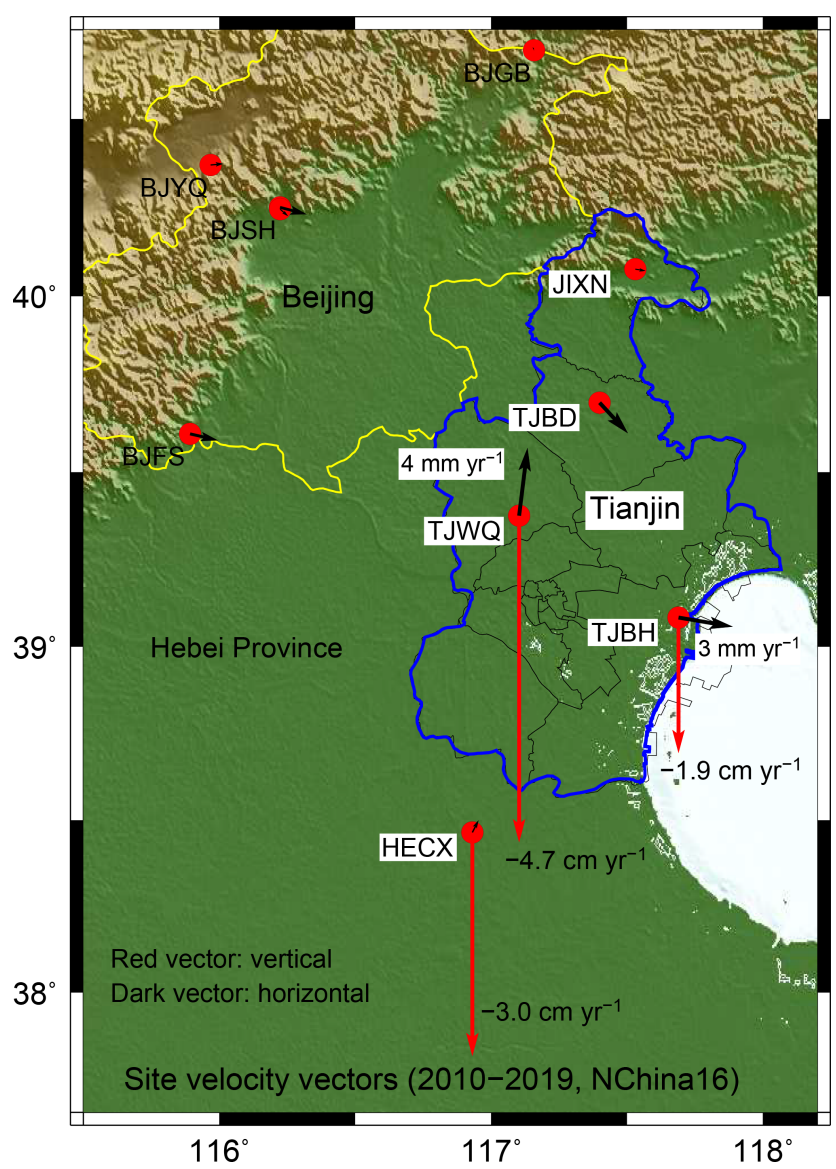

Figure 2. Vertical (red) and horizontal (dark) site velocity vectors (NChina16) derived from 10-year GPS (2010-2019) observations at nine locations in Tianjin and its surrounding areas.

These stations are located on bedrock or weathered bedrock sites. None of them recorded considerable subsidence $\left(<2 \mathrm{~mm} \mathrm{yr}^{-1}\right)$. There are five CMONOC stations within or adjacent to the municipality of Tianjin (Fig. 2). Figure 3 depicts the displacement time series recorded by these five GPS stations: JIXN, TJBD, TJBH, TJWQ, and HECX.

JIXN did not record any considerable subsidence $\left(0.1 \mathrm{~mm} \mathrm{yr}^{-1}\right)$ during the 10-year period from 2010 to 2019 (Fig. 3). JIXN is in Jizhou district, formerly a county known as Jixian. TJBD recorded minor subsidence $\left(0.2 \mathrm{~mm} \mathrm{yr}^{-1}\right)$. TJBD is in Baodi district. Jizhou and Baodi are two districts in the far north of the municipality of Tianjin, far away from the industrial and commercial areas. The two districts cover the least economically developed regions and have smaller population density compared to the other districts of Tianjin. The two districts probably use less groundwater than other districts. Furthermore, the thickness of Quaternary aquifers in the north is less than in the south. As a result, these two districts have not been considerably affected by subsidence.

TJBH recorded moderate subsidence at an average rate of approximately $2 \mathrm{~cm} \mathrm{yr}^{-1}$ during 2010-2019. TJBH is in Bin- 
hai district, a coastal district located on the west coast of the Bohai Gulf and east of Tianjin's main urban area. Binhai district has undergone rapid industrial and infrastructure development since the 2000s.

TJWQ recorded rapid subsidence with a steady rate of approximately $5 \mathrm{~cm} \mathrm{yr}^{-1}$ from 2010 to 2019. TJWQ is in Wuqing district, which has been experiencing rapid urbanization during the past three decades (1990s-2010s). Wuqing has a unique location advantage called "Corridor of Beijing and Tianjin". The population has reached over 1 million as 2018. Groundwater is still a significant component of public water supply and water use in agriculture and local industry. The horizontal components of TJWQ also recorded a steady movement towards the north with an average velocity of approximately $4 \mathrm{~mm} \mathrm{yr}^{-1}$. The horizontal movement associated with the rapid subsidence implies that this station is not located in the center of the ongoing subsidence bowl. The subsidence rate in the center could be more significant. Indeed, a subsidence rate of $15 \mathrm{~cm} \mathrm{yr}^{-1}$ in Wuqing was reported by Zhang et al. (2016) based on Interferometric Synthetic Aperture Radar (InSAR) observations during the period from 2012 to 2014. Other researchers also reported much faster subsidence in Tianjin during the 2000s and 2010s (Ye et al., 2016; Liu et al., 2016; Gong et al., 2018).

HECX is located in Cangzhou city in Hebei Province, $20 \mathrm{~km}$ away from the border of Tianjin and Hebei Province. Cangzhou is a rapidly developing industrial city with a population of over one million as of 2019. HECX recorded steady subsidence of $2.4 \mathrm{~cm} \mathrm{yr}^{-1}$ during the period from 2010 to 2014; the subsidence accelerated to $3.7 \mathrm{~cm} \mathrm{yr}^{-1}$ since 2015. The total subsidence during 2010-2019 at HECX is as much as $30 \mathrm{~cm}$.

\subsection{Comparisons of the maximum subsidence rates in Tianjin, Houston, and Mexico City}

Our research group is also studying urban subsidence in Houston, US and Mexico City, Mexico. Houston and Mexico City have been suffering from subsidence problems for a century. According to numerous investigations, excessive groundwater withdrawal is the primary cause of ongoing subsidence in all three cities: Tianjin, Houston, and Mexico City (e.g., Chaussard et al., 2014; Yu and Wang, 2016).

The ongoing $4.7 \mathrm{~cm} \mathrm{yr}^{-1}$ subsidence at TJWQ is among the most rapid subsidence ever recorded by long-history continuous GPS in China, which is comparable to the most rapid subsidence in the Houston metropolitan region from the 1990s to early 2000s (Kearns et al., 2015). The subsidence rate in the Houston region has been successfully reduced by groundwater regulations enforced by local subsidence districts since the 1970s. According to recent studies (Kearns et al., 2019), currently, the most rapid subsidence in the greater Houston region is approximately $2 \mathrm{~cm} \mathrm{yr}^{-1}$ with respect to a stable local reference frame (Houston16) (Fig. 4). The mod-

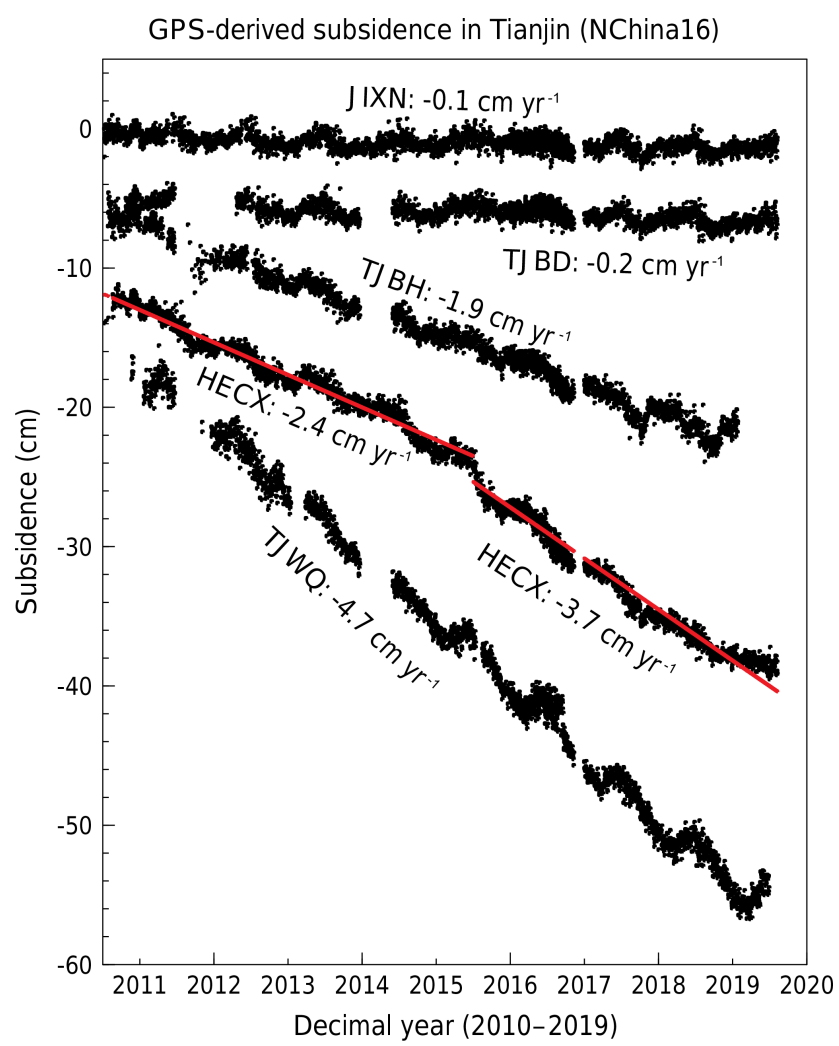

Figure 3. Subsidence time series recorded by four GPS stations (JIXN, TJBD, TJBH, TJWQ) within and one (HECX) adjacent to the municipality of Tianjin.

erate subsidence is occurring in Katy and The Woodlands, two affluent and rapidly developing suburbs to the west and north of Houston, respectively.

According to our recent investigations, rapid subsidence $\left(>\mathrm{cm} \mathrm{yr}^{-1}\right.$ ) is ongoing in several cities in central Mexico (Yu and Wang, 2017; Wang et al., 2020). A GPS station (MMX1) in Mexico City recorded steady subsidence of approximately $27 \mathrm{~cm} \mathrm{yr}^{-1}$ with respect to a stable regional reference frame (Gulf of Mexico reference frame) since 2008 (Fig. 4). To our knowledge, the $27 \mathrm{~cm} \mathrm{yr}^{-1}$ subsidence is the most rapid urban subsidence ever recorded by continuous GPS. MMX1 is located in the Mexico City International Airport and has experienced approximately $3 \mathrm{~m}$ total subsidence during 2010 to 2019. Du et al. (2019) reported that InSAR observations (2004-2018) also revealed an approximately $30 \mathrm{~cm} \mathrm{yr}^{-1}$ subsidence rate in the area adjacent to the airport.

\section{Seasonal ground deformation}

GPS-derived positional time series are well known to have periodic variations attributed to a combination of annual and seasonal cyclical sinusoids. The cyclical signals could be the result of a combination of actual periodical ground motions (up and down) and periodical errors associated with the 


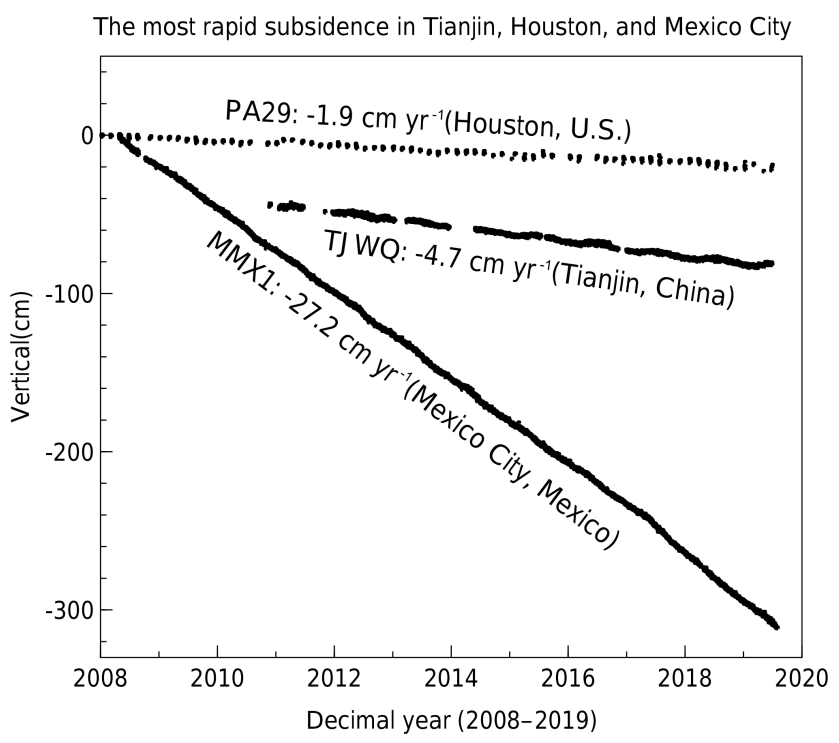

Figure 4. Comparisons of the most rapid ongoing subsidence recorded by GPS in Tianjin (China), Houston (US), and Mexico City (Mexico).

PPP processing. It is often difficult to distinguish the individual sources that cause the seasonal motions superimposed into the GPS-derived displacement time series (Wang et al., 2015).

A seasonal ground deformation model (vertical) in north China was developed by Wang et al. (2018) based on longperiod GPS observations at weathered bedrock sites, which can be described as:

$$
\begin{aligned}
\operatorname{Seasonal}_{\mathrm{UD}}(t) & =-0.35 \times \cos (2 \pi t)+0.45 \times \sin (2 \pi t) \\
& +0.1 \times \cos (4 \pi t)-0.13 \times \sin (4 \pi t)
\end{aligned}
$$

where $t$ is time with a unit of decimal year. The unit of the seasonal motion is in $\mathrm{cm}$. The seasonal model could be useful for the near-real-time landslide or structural deformation monitoring since the seasonal model predicts much of the up-coming noise (Bao et al., 2017).

Figure 5 depicts a comparison of the seasonal model (red) with GPS-derived seasonal ground motions (dark) in Tianjin. The vertical displacement time series are obtained by applying a smoothing ( $7 \mathrm{~d}$ average) process on the daily displacement time series (detrended) illustrated in Fig. 3. Overall, the vertical displacement time series in Tianjin agree considerably well with the regional seasonal-model. On average, the peak-to-trough amplitude is approximately $2 \mathrm{~cm}$. TJWQ recorded a larger peak-to-trough amplitude (approximately $3 \mathrm{~cm}$ ) than other stations.

It appears that the seasonal motions are dominated by a 4month-long downward movement (subsidence) from June to September and an 8-month upward movement (uplift) from October to next May. In general, periodic ground oscillations in soft sediments areas are controlled by seasonal variations

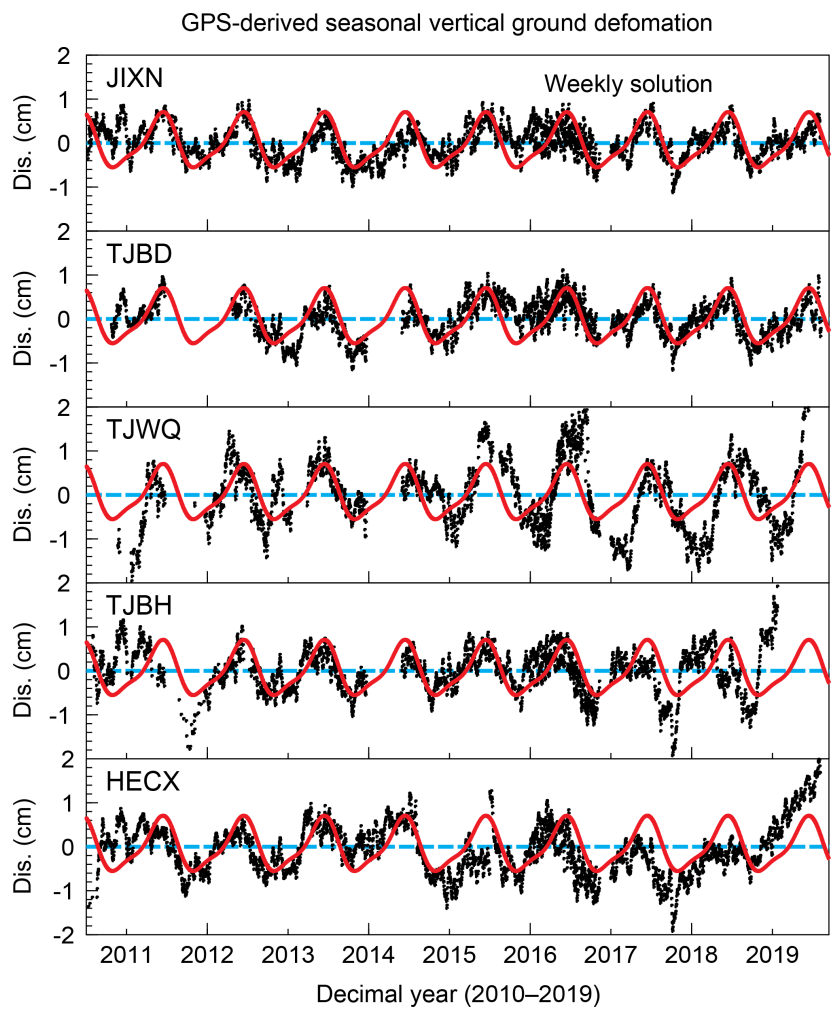

Figure 5. Comparisons of seasonal vertical ground deformation recorded by GPS (dark, $7 \mathrm{~d}$ average) in Tianjin with the seasonal model (red, Eq. 1) for the north China region.

in the groundwater level, surface water loading, snow loading, and soil moisture. The groundwater level is generally lower during June through September compared to the rest of the year because groundwater withdrawals during these months are usually at an annual maximum. In general, more groundwater is used during the summer months compared to the winter months.

\section{Summary and Conclusions}

Large CORS networks have been established in many countries for land surveying and crustal monitoring purposes, which also recorded important land subsidence information, as a by-product. This study investigated CMONOC stations within and adjacent to the municipality of Tianjin. Ongoing subsidence as fast as approximately $5 \mathrm{~cm} \mathrm{yr}^{-1}$ was recorded in Wuqing, 3 to $4 \mathrm{~cm} \mathrm{yr}^{-1}$ was recorded in Cangzhou, and $2 \mathrm{~cm} \mathrm{yr}^{-1}$ was recorded in Binhai. The subsidence rates at TJWQ and TJBH were steady from 2010 to 2019; however, the subsidence at HECX accelerated since 2015. According to previous investigations, the rapid ongoing subsidence is caused by substantial groundwater withdrawals associated with rapid urban and industrial development.

GPS-derived subsidence time series presented in this study depict substantial spatial and temporal variations of subsi- 
dence rates. The spatial variation may be associated with the differences among sites in the ratios of sand, silt, and clay, the amount of nearby groundwater withdrawal, and previously established preconsolidation heads. The temporal variations are mostly correlate with groundwater levels during different periods. As a result, it is a challenge to precisely estimate subsidence risk at a specific site by extrapolating or inferring rates of subsidence observed from adjacent sites during the same time window, or by extrapolating or inferring rates of historic subsidence at the same site. Certainly, the observations at a few GPS sites would not provide enough information to assess the overall ongoing subsidence in Tianjin. However, they may provide credible "ground truth" and constraints to calibrate or validate the subsidence estimations provided by numerical modeling and other remote sensing techniques, such as Interferometric Synthetic Aperture Radar (InSAR). The long-term GPS measurements also provide first-hand ground truth datasets for local governments to assess subsidence risk and make plans for future urban development.

Data availability. The GPS-derived subsidence time series presented in this article are available to the interested researchers by directly contacting the first author of this article (zhao.rb@tcu.edu.cn).

Author contributions. RZ and GW prepared the original draft. All authors edited, reviewed, and improved the manuscript.

Competing interests. The authors declare that they have no conflict of interest.

Special issue statement. This article is part of the special issue "TISOLS: the Tenth International Symposium On Land Subsidence - living with subsidence". It is a result of the Tenth International Symposium on Land Subsidence, Delft, the Netherlands, 17-21 May 2021.

Acknowledgements. The authors acknowledge the Crustal Movement Observational Network of China (CMONOC) for providing GPS data.

Financial support. This research was supported by the Key Laboratory of Soft Soil Engineering Character and Engineering Environment of Tianjin at the Tianjin Chengjian University, the Key Laboratory of Urban Security and Disaster Engineering of the Ministry of Education (China) at the Beijing University of Technology, the Key Laboratory for Digital Land and Resources of Jiangxi Province at East China University of Technology (grant no. DLLJ201616), and the National Science Foundation of China (grant no. 51829801).

\section{References}

Bao, Y., Guo, W., Wang, G., Gan, W., Zhang, M., and Shen, S.: Millimeter-accuracy structural deformation monitoring using stand-alone GPS: case study in Beijing, China, J. Surv. Eng., 144, 05017007, https://doi.org/10.1061/(ASCE)SU.19435428.0000242, 2017.

Bertiger, W., Desai, S., Haines, B., Harvey, N., Moore, A., Owen S., and Weiss, J.: Single receiver phase ambiguity resolution with GPS data, J. Geodesy, 84, 327-337, https://doi.org/10.1007/s00190-010-0371-9, 2010.

Chaussard, E., Wdowinski, S., Cabral-Cano, E., and Amelung, F.: Land subsidence in central Mexico detected by ALOS InSAR time series, Remote Sens. Environ. 140, 94-106, https://doi.org/10.1016/j.rse.2013.08.038, 2014.

Du, Z., Ge, L., Ng, A. H., Zhu, Q., Zhang, Q., Kuang, J., and Dong, Y.: Long- term subsidence in Mexico City from 2004 to 2018 revealed by five synthetic aperture radar sensors, Land Degrad. Dev., 30, 1785-1801, https://doi.org/10.1002/ldr.3347, 2019.

Guo, W., Wang, G., Bao, Y., Li, P., Zhang, M., Gong, Q., Li, R., Gao, Y., Zhao, R., and Shen, S.: Detection and monitoring of tunneling-induced riverbed deformation using GPS and BeiDou: a case study, Appl. Sci., 9, 2759, https://doi.org/10.3390/app9132759, 2019.

Gong, H., Pan, Y., Zheng, L., Li, X., Zhu, L., Zhang, C., Huang, Z., Li, Z., Wang, H., and Zhou, C.: Long-term groundwater storage changes and land subsidence development in the North China Plain (1971-2015), Hydrogeol. J., 26, 1417, https://doi.org/10.1007/s10040-018-1768-4, 2018.

Hu, R. L., Yue, Z. Q., Wang, L. C., and Wang, S. J.: Review on current status and challenging issues of land subsidence in China, Eng. Geol., 76, 65-77, doi.org/10.1016/j.enggeo.2004.06.006, 2004.

Kearns, T. J., Wang, G., Bao, Y., Jiang, J., and Lee, D.: Current land subsidence and groundwater level changes in the Houston metropolitan area, Texas (2005-2012), J. Surv. Eng., 05015002, 1-16, https://doi.org/10.1061/(ASCE)SU.19435428.0000147, 2015.

Kearns, T. J., Wang, G., Turco, M., Welch, J., Tsibanos, V., and Liu, H.: Houston16, A stable geodetic reference frame for subsidence and faulting study in the Houston metropolitan area, Texas, US, Geod. Geodyn., 10, 382-293, https://doi.org/10.1016/j.geog.2018.05.005, 2019.

Liu, P., Li, Q., Li, Z., Hoey, T., Liu, G., Wang, C., Hu, Z., Zhou, Z., and Singleton, A: Anatomy of Subsidence in Tianjin from Time Series InSAR, Remote Sens., 8, 266, https://doi.org/10.3390/rs8030266, 2016.

Liu, Y., Sun, X., Wang, G., Turco, M. J., Agudelo, G., Bao, Y., Zhao, R., and Shen, S.: Current activity of the Long Point Fault in Houston, Texas constrained by continuous GPS measurements (2013-2018), Remote Sens., 11, 1213, https://doi.org/10.3390/rs11101213, 2019.

Rebischung, P., Altamimi, Z., Ray, J., and Garayt, B: The IGS contribution to ITRF2014, J. Geodesy, 90, 611-630, https://doi.org/10.1007/s00190-016-0897-6, 2016.

Tianjin Geological Survey and Mine Resource Administration: Regional Geology of Tianjin Municipality, Geology Press, Beijing, 1992 (in Chinese). 
Wang, G. and Soler, T.: Measuring land subsidence using GPS: ellipsoid height vs. orthometric height, J. Surv. Eng., 141, 1-12, https://doi.org/10.1061/(ASCE)SU.1943-5428.0000137, 2014.

Wang, G., Kearns, T. J., Yu, J., and Saenz, G.: A stable reference frame for landslide monitoring using GPS in the Puerto Rico and Virgin Islands region, Landslides, 11, 119-129, https://doi.org/10.1007/s10346-013-0428-y, 2014.

Wang, G., Bao, Y., Cuddus, Y., Jia, X., Serna, J., and Jing, Q.: A methodology to derive precise landslide displacement time series from continuous GPS observations in tectonically active and cold regions: a case study in Alaska, Nat. Hazards 77, 1939-1961, https://doi.org/10.1007/s11069-015-1684-z, 2015.

Wang, G., Turco, M., Soler, T., Kearns, T. J., and Welch, J.: Comparisons of OPUS and PPP solutions for subsidence monitoring in the greater Houston area, J. Surv. Eng., 143, 05017005, https://doi.org/10.1061/(ASCE)SU.1943-5428.0000241, 2017.

Wang, G., Bao, Y., Gan, W., Geng, J., Xiao, G., and Shen, S.: NChina16, A stable geodetic reference frame for geological hazard studies in North China, J. Geodyn., 115, 10-22, https://doi.org/10.1016/j.jog.2018.01.003, 2018.

Wang, G., Liu, H., Mattioli, G., Miller, M., Feaux, K., and Braun, J.: CARIB18, a stable geodetic reference frame for geological hazard monitoring in the Caribbean region, Remote Sens., 11, 680, https://doi.org/10.3390/rs11060680, 2019.
Wang, G., Zhou, X., Wang, K., Ke, X., Zhang, Y., Zhao, R., and Bao, Y.: GOM20, a stable geodetic reference frame for subsidence, faulting, and sea-level rise studies along the coast of the Gulf of Mexico, Remote Sens., 12, 350, https://doi.org/10.3390/rs12030350, 2020.

Ye, S., Xue, Y., Wu, J., Yan, X., and Yu, J.: Progression and mitigation of land subsidence in China, Hydrogeol. J., 24, 685-693, https://doi.org/10.1007/s10040-015-1356-9, 2016.

Yi, L., Zhang, F., Xu, H., Chen, S., Wang, W., and Yu, Q.: Land subsidence in Tianjin, China, Environ. Earth Sci. 62 1151-1161, https://doi.org/10.1007/s12665-010-0604-5, 2011.

Yu, J. and Wang, G.: GPS-derived ground deformation (2005-2014) within the Gulf of Mexico region referred to a stable Gulf of Mexico reference frame, Nat. Hazards Earth Syst. Sci., 16, 15831602, https://doi.org/10.5194/nhess-16-1583-2016, 2016.

$\mathrm{Yu}$, J. and Wang, G.: Introduction to the GNSS geodetic infrastructure in the Gulf of Mexico Region, Surv. Rev., 352, 51-65, https://doi.org/10.1080/00396265.2015.1108069, 2017.

Zhang, Y., Wu, H., Kang, Y., and Zhu, C.: Ground subsidence in the Beijing-Tianjin-Hebei region from 1992 to 2014 revealed by multiple SAR stacks, Remote Sens., 8, 675, https://doi.org/10.3390/rs8080675, 2016. 